\title{
Nanoparticles Based Carbon Paste Electrodes for the Determination of Flupentixol Dihydrochloride: Application to Pharmaceutical Analysis and Pharmacokinetic Study
}

\author{
Nehad A. Abdallah \\ Pharmacognosy and Pharmaceutical Chemistry Department, Faculty of Pharmacy, Taibah University, \\ Al-Madinah Al-Mounawarah, KSA, Postal code: 41477 \\ Experimental and Advanced Pharmaceutical Research Unit (EAPRU), Faculty of Pharmacy, Ain \\ Shams University, Cairo, Egypt, Postal code: 11566 \\ E-mail: nehad.amin@gmail.com
}

doi: $10.20964 / 2016.12 .04$

Received: 28 June 2016 / Accepted: 9 September 2016 / Published: 10 November 2016

Five different carbon paste electrodes were developed and applied for the electrochemical determination of flupentixol dihydrochloride. Sensor 1 was fabricated using a mixture of graphite powder and multiwall-carbon-nanotubes. Different additives were used to improve the performance and the sensitivity of the carbon paste electrode. Sensor 2 was developed using chitosan in addition to the graphite powder and the multiwall-carbon-nanotubes while sensor 3 was fabricated with the addition of calix[4]arene ionophore. Copper nanoparticles were incorporated in the membrane paste of sensor 4. Sensor 5 was fabricated using a mixture of copper nanoparticles, multiwall-carbon-nanotubes and calix[4]arene in a graphite paste. The studied carbon paste electrodes exhibited the best performance characteristics with slopes of 29.7, 28.8, 30.2, 30.7 and 30.8 (mV / concentration decade) and linear concentration ranges of $1.0 \times 10^{-5}-1.0 \times 10^{-2}, 1.0 \times 10^{-6}-1.0 \times 10^{-1}, 1.0 \times 10^{-7}-1.0 \times 10^{-2}$, $1.0 \times 10^{-9}-1.0 \times 10^{-2}$ and $1.0 \times 10^{-10}-1.0 \times 10^{-2} \mathrm{~mol} \mathrm{~L}^{-1}$ for sensors $1,2,3,4$ and 5 , respectively. The sensors linear ranges deviated from their ideal ranges after 40, 46, 58, 63 and 82 days for sensors 1, 2, 3,4 and 5, respectively. All the proposed sensors were successfully used for the determination of flupentixol dihydrochloride in bulk, tablets dosage forms and human plasma samples.

Keywords: Flupentixol; copper nanoparticles; multiwall-carbon-nanotubes; pharmacokinetics; dissolution.

\section{FULL TEXT}

(C) 2016 The Authors. Published by ESG (www.electrochemsci.org). This article is an open access article distributed under the terms and conditions of the Creative Commons Attribution license (http://creativecommons.org/licenses/by/4.0/). 